\title{
Community Medicine as Racial Justice
}

\section{An Interview with Tenisha Dandridge, Cofounder and President of the Black Acupuncturist Association (US)}

\author{
Yi-Li Wu | ORCID: 0000-0003-4375-0672 \\ Department of Women's and Gender Studies and Department of History, \\ University of Michigan, Ann Arbor, MI, USA \\ yiliwu@umich.edu
}

Tenisha Dandridge | ORCID: 0000-0003-1234-2510

Everyone's Place, Sacramento, CA, USA

tenisha@everyones-place.com

\begin{abstract}
Tenisha Dandridge is a cofounder and the current president of the Black Acupuncturist Association (US). She advocates using Chinese medicine and acupuncture to address the racial health disparities afflicting African Americans. In June 2020 an editor of Asian Medicine interviewed her about her career and medical activism. The main themes of the interview include: how racial bias results in disproportionately high rates of morbidity and mortality among African Americans; how the theories and therapies of Chinese medicine are well suited for addressing the psychophysiological harms caused by racial discrimination; why it is important to increase Black representation in the acupuncture profession; and how community-based modes of healing can expand African Americans' interest in, access to, and utilization of acupuncture and ear seed acupressure.
\end{abstract}

\section{Keywords}

Racial health disparities - Black Acupuncturist Association - acupuncture - ear seeds - community healing 
Tenisha Dandridge, L.Ac. (Licensed Acupuncturist), is a native of Sacramento, California, where she leads the mobile acupuncture clinic Everyone's Place. She received a Bachelor of Science degree in natural health sciences and a Master of Science degree in acupuncture and Chinese medicine from the Kenmore, Washington, campus of Bastyr University (bastyr.edu), and a doctorate from the Pacific College of Health and Science (pacificcollege.edu). She is a cofounder of the Black Acupuncturist Association (blackacupuncturist.org), for which she currently serves as president.

Yi-Li Wu, senior editor of Asian Medicine, spoke with Dandridge over Zoom on June 27, 2020, to learn about her experiences as a student and practitioner of Asian medicine, her blog post on the role of Black Panther community clinics in creating and disseminating acupuncture knowledge, and her vision of using Asian medicine to rectify racial disparities in health care in the United States. In the month prior to this interview, the police murder of George Floyd in Minneapolis, MN, had sparked massive antiracism protests across the US and around the globe. At a moment of intense national soul-searching, what was originally scheduled as a one-hour interview turned into a two-and-a-halfhour conversation. The following account has been excerpted and condensed from the conversation transcript and edited for style and clarity.

Wu: You started off majoring in engineering in college [at Morgan State University, Baltimore, MD]. How did you decide to become an acupuncturist?

Dandridge: By the time I went to Morgan I had a number of health complaints, and top of the list were breathing issues and menstrual health issues. I had a horrible [menstrual] cycle; I had standing orders to stay at home and to take Percocet ${ }^{1}$ and skip classes and tests. Then I had a grandmother whom I lost; she was one of my dearest and closest family members. She was really my first introduction to natural medicine, and when I lost her, it made me start to question how many prescriptions I was taking, and the fact that nothing was getting better. Then there came this day - it was actually Christmas Eve - and I had this ground beef in my refrigerator. I'm not sure how long this ground beef had been in my refrigerator, but it was too long. I was around nineteen, twenty years old, and I was sick within thirty minutes of eating this thing, and within two hours I could barely move.

I ended up being taken out of my house in an ambulance to Good Samaritan Hospital in Baltimore. When I got there I said, "My stomach hurts, I'm super

1 Percocet is the brand name of a prescription painkiller that combines oxycodone hydrochloride with acetaminophen. It is a highly addictive opioid. 
nauseous, I have a lot of pain." And they said, "Oh, well, you're probably pregnant." When the urine analysis came back negative for pregnancy, they did a blood test. When the blood test came up negative for pregnancy, they did an intravaginal wand, to see if I had any ectopic pregnancy. And when they did the intravaginal wand, they found a cyst, and said, "Oh, well then, you probably have an STI [sexually transmitted infection]." I said, "Nope, again, that's not it. I had this hamburger, it was really old, I ate it, and within a short amount of time I started to feel really not okay." And they were like, "No, we're going to go test you for STIs now." So, they tested me for all the STIs, and the conversation went from, "We can't find an STI, you definitely have a cyst and a couple [of] white blood cells," to "You definitely have a strange, mysterious STI!" And they hospitalized me for pelvic inflammatory disease and called in a specialist to find out what was wrong with me. Now, medical racism, right? ${ }^{2}$ [Laughs]

And so I met Dr. Lee. I wish I could still find his card because the man changed my life. Dr. Lee came in and gave me a gynecological exam. He kind of scratched his head, he had this sort of confused look on his face, and he was just like, "Why are you here?" I told him the story, how I was deathly ill within two hours of eating this hamburger. He looked at me, really frustrated and really confused; like you can see this man's head beginning to catch fire. He says, "Did you tell this story to the people who admitted you?" "Yes." "Are you sure you told this story to the people who admitted you?" "Yes." At which point, Dr. Lee began to cuss out everybody. 'Cause this is Christmas Day, at this point! This man is a specialist [in gynecology] and he just got called in for food poisoning!

Before this whole encounter was over, Dr. Lee told me, "Well, look. I get it that your cycles suck, and if you want to get your cycles under control, then

2 An important indicator that researchers examine in studies of racial bias in medicine is how well the practitioner communicates with, listens to, and empathizes with patients of different ethnicities. Studies have repeatedly shown that doctors are less responsive to the concerns and symptoms reported by Black patients than by white patients (e.g., Hoffman et al. 2016; Park et al. 2020). As a result, they are also less likely to prescribe needed therapeutic measures, such as tests or pain relief medications. These medical biases are rooted in racist stereotypes that depict Black people as hypersexualized, unintelligent, less sensitive to pain, and more prone to drug abuse. Such biases are also believed to contribute to the fact that Black maternal mortality rates are two to three times higher than that of whites. Numerous accounts document how Black women, including tennis star Serena Williams, suffer lifethreatening or fatal consequences because doctors refuse to listen to them. See, for example, Martin and Montagne 2017; Lockhart 2018; Stallings 2018; Cooper Owens 2021. In August 2021 the US Centers for Disease Control and Prevention (CDC) launched the "Hear Her" campaign to reduce maternal mortality by encouraging people to take seriously the self-reported symptoms of pregnant and postpartum women. Although it did not explicitly mention race, it prominently featured images and videos of Black women. See Stinson and Bucherati 2020. 
here's my card." So I called him, I made my appointment, and I went in. One of the changes he made is that he changed my birth control. And he gave me this little piece of paper and it had kanji on it. ${ }^{3}$ And he said, "I want you to go to the store."

And there was this little random Chinese herbal store, and I took the kanji in and I gave it to the lady and she showed me this bottle of tar. It was black and it definitely had some kind of licorice in it, and it was lumpy and it was nasty. I thought, "I don't think I can choke this down." But nothing that I had tried up to that point worked. So, I drank the tar. ${ }^{4}$

I was terribly inconsistent with drinking the tar, but only about three weeks into drinking it, I had my first [menstrual] cycle, and it was a lot better. I didn't need Percocet. I still needed regular Ibuprofen, ${ }^{5}$ and I still needed [to sit on] a towel, but I didn't need narcotics in order to not feel like my uterus was going to - like in Alien - jump out and have something try to eat me [laughing]. ${ }^{6}$ So, okay, I'll keep drinking the tar. The second cycle came around, and I didn't need the towel, and I could get away with a couple of Ibuprofen instead of eating them like Tic Tacs. ${ }^{7}$ I was like, "Okay, the tar is not that bad! I'm going to keep doing my best to eat the tar." Then the third cycle came around, and this is what blew my mind: less than ninety days into it, I was sitting in class and I'm thinking, "I need to go check myself, because I feel like I peed on myself and this is not correct." And I had blood on myself! And the amazing thing was, I had had no PMS [premenstrual syndrome], I had had no breast distension, I had no cramps, I had no headaches, I had no nausea; my cycle could still be controlled by pads because it was a regular cycle, for all intents and purposes!

I had a checkup with Dr. Lee and I said, "Dude, what is in the tar?" He said, "Well, Chinese medicine." And I'm like, "Great, so how can I go learn what the tar is?" He said, "I am from China, and I learned Chinese medicine in China, and I did this back home and now I just continue to use the information here." And I'm thinking, "Okay, you're helping but not helping, and I need to find out how to do the magic tar."

3 Dandridge is using the Japanese pronunciation of 漢字, meaning "Chinese characters" (Ch. Hanzi).

4 The use of herbal remedies to treat menstrual disorders has long been a core focus of Chinese "medicine for women" ( fu ke 婦科). See, for example, Furth 1999.

5 A painkiller available over the counter, as opposed to a prescription drug like Percocet.

6 Dandridge is referencing a famous scene from the 1979 film Alien, directed by Ridley Scott. A malicious parasitic extraterrestrial that has been gestating inside the body of a spaceship crew member reaches maturity, causing acute pain and convulsions in its unfortunate host. It then bursts out of his chest, killing him.

7 Tic Tacs are a brand of small, pill-shaped mint candies, packaged in a pocket-sized dispenser box. 
Then I met the guy who became my next mentor, and he was an acupuncturist! The first guy ever to stick me with needles. And I'm like, "I'm not quite sure what's up with the magic tiny swords or the magic tar, but I need to learn how to do this! 'Cause this is way cooler than engineering! Forget engineering! Engineering sucks!" And it did. I didn't want to go back to school for engineering or computer science; it gave me absolute panic attacks. My mentor said, "If you're going to go study Chinese medicine, go study it for real, and go get a degree in it and become a respectable healer." I said, "I can't, I would have to go to China." He said, "You don't have to go to China! Go to Bastyr!" And I didn't question it, I didn't look back. Bastyr was there, and I could get my degree. I could get a real license. I could be a real healthcare provider. And that's exactly what I did!

Now, was my family pleased that I was leaving a respectable position in electrical engineering with a minor in computer science when I had an academic scholarship? No! My family was like, "Can you at least be a nurse? Could you do something better than acupuncture?" And I was like, "No, I'm going to do this, because this stuff is amazing." So I went to Bastyr. I've been practicing for eleven years now, and I'm so happy. This is the only time where I can say that medical racism was a good thing because if this series of events hadn't happened, I would never have been introduced to traditional Chinese medicine.

Wu: After you got your degree from Bastyr, you started practicing, and at some point you went to get a doctorate in acupuncture. What happened in between that made you decide to do that?

Dandridge: What I had found over the years I had been practicing up to that point was that people still do not trust traditional Chinese medicine, people do not trust acupuncture, and people would frequently tell me, "Well, I'm going to check with my doctor first.” Even though I couldn't at that time call myself a doctor, we [acupuncturists] are considered primary care providers in California, and I had kind of gotten tired of hearing that. ${ }^{8}$ So, I did it honestly just to make people shut up and listen to me. You know, I have this whole series of things that hang over my head that keep people from listening to me: I'm African American, I'm female, and I'm in this weird medicine called traditional Chinese medicine and acupuncture. To a lot of people, my knowledge is not sacrosanct and standalone in and of itself. I found myself constantly arguing with people who'd say, "I'm going to go check with my doctor first." And it was like, "I think I need these two initials somewhere in my name, because

8 Acupuncture was designated a "primary healthcare profession" in California in 1978. "Acupuncture Board History," n.d. 
I know that I can help people. I have no doubt in my mind that I can help you." What I have found is that since I've able to add the "Dr." in front of my last name, I don't hear that quite as often, and there's more respectability to what I do.

And then, my icing, my cherry, my topper, was "Well, if I'm going to go do this doctorate, then I can do research on the thing that I wanted to do anyway, which is marrying acupuncture and traditional Chinese medicine with closing the racial health disparities gap." Even before I started my doctorate, I understood clinically that I had a hard time treating people of color and getting them to be better. We all know the things that African Americans suffer from more than everybody else, ${ }^{9}$ but I needed to have a deeper understanding. So I put them together, and that is when I really got started getting into the research of using acupuncture and traditional Chinese medicine to address the health disparities gaps, the transgenerational trauma, ${ }^{10}$ and the racial battle fatigue ${ }^{11}$ that people of color suffer from in colonized countries. I say the US because I live here and this is where I focus, but it's colonized countries ${ }^{12}$ that have these issues; it's not just America. And I was super dismayed, as I was going through my doctorate program, at how many people were truly clueless about this topic.

Wu: So when you went back for your doctorate, it gave you a moment to focus on things you had been noticing clinically. And what you are seeing is patterns of psychological distress that are racially linked; that are salient in African American and Latinx ${ }^{13}$ communities, for example, that you are not going to

$9 \quad$ For a landmark study on racial and ethnic inequities in US health care, see Institute of Medicine 2003.

10 "Transgenerational trauma" refers to the ways in which the physical and psychological effects of mass cultural or social trauma may be transmitted from one generation to the next. A survey of recent directions in research on transgenerational trauma is DeAngelis 2019 .

11 Critical race theorist William A. Smith first coined the term "racial battle fatigue" to analyze the stress-induced ailments experienced by Black professors who had to continuously combat racist biases when working in predominantly white institutions. See Smith 2004. The term is now widely used to describe the effects of cumulative chronic racismrelated stressors on racially marginalized groups.

12 Dandridge's description of the US as a colonized country echoes academic studies that show how the nation's history and self-identity are characterized by "settler colonialism." Settler colonialism is a mode of domination whereby "an exogenous collective aims to locally and permanently replace indigenous ones" (Veracini 2016, 4). It thus depends on the active perpetuation of white supremacy and related racist ideologies that serve to dehumanize and erase the experiences of those who are removed.

13 In US discussions of race and equity, the term Latinx is often used as a gender-neutral substitute for the conventional term "Latino," the feminine equivalent of which is "Latina." 
see in the white population. And people in Asian medicine are not necessarily aware of these social determinants of illness, even though they're supposed to be?

Dandridge: They're supposed to notice, right? And what I noticed in my clinical practice kind of hit like a pimple-popping moment, when I read Post Traumatic Slave Syndrome by Dr. Joy DeGruy ${ }^{14}$ and I was like "Duh! How did I miss this for so long?" So the biggest clinical differences that I noticed were two things.

One, people of color didn't want to come and get acupuncture, and it's really different on the East Coast versus the West Coast. Part of that is that there's this really deep East Coast history of the [Black] Panthers and Mutulu [Shakur]'s involvement in the Lincoln Detox Center. ${ }^{15}$ And the East Coast has a bazillion little things in this tiny little space, whereas California's all spread out. They had the wonderful doctor Tolbert Small, but it was just in Oakland [California], and that medicine didn't really spread the way that it did on the East Coast. ${ }^{16}$ On the East Coast, I noticed that people of color were way more interested in natural medicine, and way more willing to come see an African American practitioner. On the East Coast my practice was almost 100 percent Black. On the West Coast, I have a really hard time getting people of color to come see me. It's not that I don't have African American clients, but it's not the same.

And [two], what I noticed is that I had a really hard time getting things [in the body] to move and to get better in African American communities. But then I treat a white person and, like, three treatments in, they're done, they're good, there's no problems; they come in for their maintenance. It was perceptible how much faster white people got better in comparison to Black people! I'm like, "Why is it so hard?" And, you know, I had my own internalized racism, things that I had learned at that point, like, "Well, Black people don't eat well." So I would coach people on diet. Then I would meet people who had good diets, who did the yoga, who did the working out, and they couldn't lose the weight, and they couldn't drop the diabetes, and they couldn't get the hypertension to

\footnotetext{
14 DeGruy 2017.

15 In 1970 Black and Puerto Rican revolutionaries in the South Bronx, New York City, established the Lincoln Detox Center to help fight surging rates of heroin addiction in the community. Mutulu Shakur played a key role in introducing acupuncture as a detoxification therapy. See Phan 2017, 254-58; Donovan 2020; Meng 2021a.

16 Although never a member of the Black Panther Party, Tolbert Small worked as a doctor for the BPP from 1970 to 1974 . In 1972 he accompanied а BPР delegation to China where he first learned about acupuncture. For more details, see in this special issue of Asian Medicine: Burton-Rose and Wu 2021; Meng 2021a, 2021b.
} 
be better. Their treatments would work, but only for a short amount of time, to [the point] where I'm just like, "Why is it so hard? Why is it so hard to treat us? Why is it so hard to get us to be better?" And I couldn't answer that question! I would pour so much love into these clients, like if I just love them a little harder and I just give them a lot more, they'll get better! But it required that much energy and effort just to kind of get them to stabilize, to get some kind of homeostasis, much less to get better. I had this question for the longest time. When I read Dr. Joy DeGruy's work and I realized it's because we're trying to heal on the battlefield, it finally clicked into place.

Because I fit the standards of beauty for melanated individuals, my [experience of] racism is significantly less than, say, my son's father, or even my son, because my son has this beautiful chocolate skin. ${ }^{17}$ I know [that] as he grows up, he's going to experience issues, just because - well, I hope he doesn't, right? But as it stands today, I have fear that my son could be the next Tamir Rice. ${ }^{18}$ So when I read [DeGruy's] work, and I'm looking at things like "vacant selfesteem" and "impotent rage," these words triggered тсм [traditional Chinese medicine] diagnoses in my head. ${ }^{19}$ Or when I started to read Broken Ladder ${ }^{20}$ and [learned] how it [social inequality] affects metabolism and hormones, [I realized that] we have language for that in тСм. It was such an easy correlation to me. I'm thinking, "How has no one seen this before now? If we know that stress does all of these things, why is it we can't say, 'Stress does this, and so racism is a stress."' You know, I always feel that we're gaslighted, we're patted on the head, like "Oh, well that didn't happen." Yes it did, it happened, and it's little things that happen all day long.

17 Melanin is the pigment responsible for skin color. The term "melanated" emerged in recent years as a way to refer to darker-skinned (i.e., "Black") people. Here Dandridge is also speaking about "colorism," namely the valorization of lighter skin and the denigration of darker skin, such that African Americans who are darker are considered less attractive and face more prejudice. Colorism is common in many societies, as shown by the global market in skin whiteners (including in Asia). See, for example, Glenn 2008.

18 Tamir Rice was a twelve-year-old African American boy shot and killed by a police officer in Cleveland, Ohio, on November 22, 2014.

19 This is a reference to two of the key patterns of negative and self-destructive emotional states that DeGruy describes as being indicative of post traumatic slave syndrome. Since TCM views pathological emotions as both the result and cause of disharmonies in the body's visceral systems, тсм therapies can in principle be used to treat emotional dysregulation. See Ye et al., 2019. 
For example, I went to IKEA yesterday, and I had at least three little racisttype events ${ }^{21}$ that happened just in the thirty minutes I was at IKEA. I'm fully aware that those three different racist experiences caused a change in my blood pressure, they caused a change in my heart function, they caused a change in the way my kidneys function, they caused a change in my capacity to reach the upper echelons of my brain, they caused all of these chemical cascades to happen in my life. And because they happened one right after the other, my body never got a chance to recover from any of them. And then I go to do the rest of my day, which is not racism-free!

When you look at this tiny little window in a person's life, and you want to know, "Well, how come African American people don't get better?" This is the reason why racism has to be declared a public health crisis. ${ }^{22}$ If it was just this one day, if it happened just this one time, that would be completely different. But because this is how our lives are, every day, you cannot heal on the battlefield, any more than a wound can heal if you're constantly picking at it. And this is what's happening in melanated communities; we don't get a break. We're just kind of constantly exhausted.

Wu: Let me ask about your blog post, "The Unusual Tale of Acupuncture, Racism, and African American history in the US," which has gotten a lot of attention lately. ${ }^{23}$ How did you come to write this, and what has the reaction been like?

Dandridge: I wrote that blog post four years ago. I don't even remember what we were protesting back in 2016, but we were protesting - pick an injustice, there are so many of them. ${ }^{24}$ And it was February - Black History Month and I was feeling my usual frustration and fatigue with trying to get African

21 Research on racial bias has shown the prevalence and negative impacts of "racial microaggressions," namely the "brief and commonplace daily verbal, behavioral, or environmental indignities, whether intentional or unintentional, that communicate hostile, derogatory, or negative racial slights and insults toward people of color" (Sue et al. 2007, 1).

22 For the calls in 2020 to declare racism a public health crisis in the US, see Bellware 2020.

23 Dandridge 2020.

24 In 2015 and 2016 racial justice activism intersected with the electoral campaign for US president, which Donald Trump eventually won in November. During the primary election season and through the general election, candidates faced sharp questioning and protests by Black Lives Matter activists and others. Calls for racial justice took on particular urgency with the rise of Donald Trump, whose campaign actively employed xenophobic and racist rhetoric and was seen as condoning white supremacy. See, for example, Johnson and Jordan 2015; Diamond 2016. 
Americans on the West Coast to use acupuncture. So I'm like, "Okay, you guys have all of this knowledge that happens in the month of February. And I think that people should know about Dr. Mutulu Shakur, and I think that they should know about the Black Panthers, because nobody seems to know this and I don't think that's correct." So this was actually a temper tantrum on paper [laughs].

At some point in time, I had gone to a POCAFest [annual conference of the People's Organization of Community Acupuncture ${ }^{25}$ ], and I had listened to [anthropologist and acupuncturist] Tyler Phan and his research into how the Black Panthers had played an integral part in [developing acupuncture treatments for drug addiction]. ${ }^{26}$ I was like, "Are you serious? How does everybody not know that Tupac [Shakur]'s stepfather was an acupuncturist?" So, as I was sitting around that February, I took one of the POcA leaflets, and [did] a good old Google search, and I paraphrased all the information that was available at the time. It was like, "Okay, I'm going to make a little blog post about it, because I'm so tired of [hearing] how wonderful [NADA founder] Michael Smith was." ${ }^{27}$ And I'm not saying Michael Smith wasn't wonderful; I'm saying that Michael Smith was brought on after Dr. [Richard] Taft ${ }^{28}$ was killed, and he was not the impetus for the NADA protocol or the utilization of acupuncture [to treat drug addiction] and that story needs to stop being told. This is whitewashing of history, and this is not acceptable.

And this whitewashing of history is one of the many reasons why people of color don't use acupuncture and they don't use traditional Chinese medicine: because we've been amputated from that part of the history. When you bring it up fifty years later, people are like, "Mmmm, you're not going to experiment on me. Needles - not okay." So this was my attempt to get the attention of the

25 The People's Organization of Community Acupuncture (POCA), formally incorporated in 2011, grew out of initiatives by two Oregon acupuncturists to make acupuncture more accessible and affordable. It does so via sliding-scale fee clinics that employ group rooms in which multiple people can receive treatment concurrently. See www.pocacoop.com.

26 Phan 2017, 254-58.

27 Michael Smith (1942-2017) was a white psychiatrist and acupuncturist who worked at the Lincoln Detox Center, subsequently becoming the director of its successor, Lincoln Recovery, in 1978. Smith founded the National Acupuncture Detoxification Association in 1985 , and he was previously credited as the sole inventor of a five-point auricular acupuncture protocol (dubbed the NADA protocol) for treating drug addiction. For the ways in which NADA began revising this history in summer 2020 to include the crucial role of Black and Puerto Rican revolutionaries at the Lincoln Detox Center, see Weeks 2020.

28 Richard Taft was a member of the medical staff at the Lincoln Detox Center, providing acupuncture treatment and training. He was found dead in a closet at the Center in October 1974. His colleagues and family alleged that he had been murdered in an attempt to discredit the Center. See People's Doctor Murdered, n.d. 
African American community, to say: "This is our history. We did this. We are attached to this. This was a part of the free Panther clinics. This was a part of the movement. This was part of the revolutionary history."29 And they didn't just treat drug addicts, right. He [Mutulu] treated people, he trained a bunch of acupuncturists, and they gave low-cost treatment and they did the whole barefoot doctor thing right there in New York!

Then I found out later that it wasn't just in New York! It was also Dr. Tolbert Small, over in Oakland. And I was like, "Oh my god, y'all! Why don't we know this?" And the crazy thing is that as much attention as this article has gotten, it has gotten attention from [within] the acupuncture community. It is super hard, to this day, to get people of color to pay attention. And that was the whole purpose of me writing the article. That blog post was a temper tantrum; me saying, "This is not the whole story. Stop leaving us out."

Wu: I'm glad you had that righteous moment of self-expression; not a temper tantrum, I think. I've recently been reading about anger, and the idea that people are afraid of anger. But sometimes anger is a really productive force.

Dandridge: It is, and I am glad that I was righteously angry, as you put it. And almost four years later, I'm still arguing with acupuncturists about the history of what happened at the Lincoln Detox Center. This is something that needs to be a part of our acupuncture curriculum. ${ }^{30}$

Wu: Let's talk about blackacupuncturist.com [the precursor to the Black Acupuncturist Association, now blackacupuncturist.org], and how it started. ${ }^{31}$ You're listed as a cofounder. Is it something that you are actively using as part of your work?

Dandridge: There are two Black acupuncture Facebook groups, and inside one of these groups there was a lady who said, "We should have a Black acupuncture organization, you know, and there used to be a Black acupuncture

29 Providing community health care was integral to the Black Panther Party's revolutionary program. See Nelson 2011.

30 Since the summer of 2020, NADA has been raising awareness of this history. In November 2020 it commemorated the fiftieth anniversary of the revolutionaries' occupation of Lincoln Hospital (NADA 202O). It subsequently launched a NADA History Series. The first event, on March 26, 2021, was an in-depth examination of the founding of the Lincoln Detox Center (NADA 2021).

31 At the time of this interview, only the website existed and the organizational structure of what is now the Black Acupuncturist Association was just starting to be formed. 
organization, BAAANA."32 And then somebody else said, "Okay, I bought a domain [name], and all you all have to do is give me your information and I'll slap it up on the website, and then we can kind of get rolling." This sat around, and [of] the now hundred-plus members of this group, nobody got to it. The original two ladies who birthed this idea, they got frustrated! Reasonably so, because nobody was responding. As I was one of the few people who were in on it, they asked, "Tenisha, what do you want to do?" And I was like, "I want to be the griot. I want to be the person who tells all the stories." ${ }^{33}$ So this sat around for a really long time, and nothing ever came of it, and it was seriously frustrating.

I thought about it and I said: "Okay, asking people for the information is obviously not working." I looked around, and I realized there were [practitioner] listings everywhere. If it's out there and it's public, then you can go get the information! So I paid somebody: "I need you to take this list of names and Google them and find their business information, and I need you to compile this list of all these people, and we're going to slap them up on this website." I felt that once there was a thing that we could anchor onto, we could get better participation. It was never just about a listing service. It was always about: "Let's reinvent BAAANA. Let's reinvent the Harlem Institute of Acupuncture." But nationally, as opposed to just in Harlem.

And now, after the sociopolitical events that have happened in the US and people taking notice of the website, it has gotten some steam behind it. Now we're having a preliminary board meeting, trying to cobble together an association so that we can do much more with it. Because that was just step one. Now that we have that attention, there are other issues that need to be addressed: a lack of education and information. Having patient education and patient information is really important to me, especially for the African American community, because there is some miseducation happening in terms of what is natural medicine, what is healthy medicine, what's good for the body and what's not. We want patient education. We want CEU classes [continuing education units for licensed professionals]; not just for all acupuncturists, but for us! We want to have opportunities where we come together because most of us practice in professional acupunctural isolation where we never see another Black acupuncturist. Practically every CEU course that I have ever gone

32 Mutulu Shakur's initiatives to provide community health care in New York City included the formation of the Black Acupuncture Advisory Association of North America (BAAANA) and the Harlem Institute of Acupuncture.

33 In many West African societies, the griot is a storyteller, of narratives both spoken and sung, who also serves as de facto community historian and the keeper of oral tradition. 
to either never has another [Black person] in the room or there's two of us. It's like reaching across from the abyss. So let's have some CEU courses and let's have some conferences for us. And then let's have some scholarships, and let's have some push into the melanated community to be able to bring people into this medicine. Let's make it a resource for our community: "our" being Black acupuncturists, and our "community" being melanated individuals and the African diaspora first.

But not just the African diaspora, because in my own research, what I have found is transgenerational trauma is really a thing. Even now, I am still convincing other acupuncturists: we know about jing, we have language for this, this is not a far leap. ${ }^{34}$ This is just adding to the tree that we should already have in our head. The issues with transgenerational trauma, the issues with domestic violence, the issues with child abuse, the issues with rape victims, the issues with First Nationers, the issues with Holocaust survivors, the issues with Hiroshima survivors, the issues with aboriginal survivors - there are so many! ... There are so many people who are dealing with so many issues where there are problems of transgenerational trauma. There is a globe-wide pandemic of transgenerational trauma, and of dehumanizing individuals. So I want this to be a resource for all of those things, and there are ideas of expanding it to include international members. We have so many goals for Black Acupuncturists [the association], but we definitely just want to be a human resource; a very profound human resource that helps to spread the magnificence of this medicine that I love so much.

Wu: I have a comment about your website. First of all, it's gorgeous. But the other thing that I was excited to see is that you have this Black woman in profile with acupuncture needles in her forehead. Usually the picture we see is the white woman with needles in her forehead. So I'm curious: did you guys do a photoshoot for that?

Dandridge: Nope, we bought it. There was a stock image, and let me tell you that [it was] like twenty-five, thirtyish dollars a pop to get those photos. There are very, very few of those, and if we ever get out of [CoviD-19] lockdown, I definitely intend to recreate some of these, or to ask some of our Black

34 The тсм term jing 精 (conventionally translated as "essence") refers to the generative vitality of the human body, endowed at conception and subsequently nurtured or impaired by life activities and experiences. It is also specifically used to refer to male and female reproductive vitalities. If parental jing is compromised as a result of disease or trauma, the constitution of any child they conceive can also be negatively affected. 
acupuncturists, "Do you have pictures that we can use?", so that we can show Black people getting acupuncture. I want some pictures from Beyoncé getting acupuncture; I want some pictures from Serena getting acupuncture; I want some pictures from Snoop Dogg getting acupuncture. Every now and then, these photos go across Instagram, and it's like "Oh my god! Look! Famous Black people doing acupuncture." I want those photos, but as it stands right now there are just not a lot of them. We need these images to be more normalized. As we have the capacity, we'll take pictures from practices, or maybe from our first conference, of all of us sitting around drinking tea with needles hanging out of us, because that's my goal for acupuncture. I want people to be able to get acupuncture like they get coffee: practically anywhere, at any point in time. You can go to the grocery store, you can go to the gas station, you can go to your local library, there's always coffee. But there's not always needles. And it needs to be that prevalent, particularly in melanated communities that are dealing with constant, enduring trauma.

Wu: Let me ask you about your \#getSHARP ear seed project. ${ }^{35}$ Is that part of what you're thinking?

Dandridge: The ear seed project came out of this idea that we can't get the needles approved across the nation, but we can get ear seeds approved, with little to no hassle, and I don't necessarily need anyone's permission to do it. It's a sticker, right? I have the class [to teach about ear seeds]; it's 94ish percent done. You'll know the science. You'll know how to find your placement. You'll know some of the history about why these things work. You'll have a couple of point combinations. You'll know where to be able to get supplies. The idea was to get the medicine out of the hands of acupuncturists, because acupuncture is expensive in a lot of cases, unless you're talking about a POCA clinic or a community acupuncture clinic.

I thought it was nonsense at first, like "Pfft! It's ear seeds! There's no point in that." But they work. They are an evidence-based medicine, and there are people who are studying the efficacy of ear seeds. ${ }^{36}$ And so if you are a hairdresser you can do this. If you are a daycare provider you can do this. If you are a mental health provider you can do this. If you work at a gas station you can do this. If you are a nail tech you can do this. Regardless of what your background is, everybody can do this. You have a tool that you can use at home to immediately

35 A project to promote the use of ear seeds, a form of acupressure in which seeds or small beads are adhered to acupoints on the ear with adhesive tape.

$3^{6}$ For a recent study of ear seed therapy for pain management, see Maryam et al. 2020. 
begin stimulating the vagus nerve, to switch it out of fight-or-flight and freeze, and back down into rest and digest. ${ }^{37}$

Again and again, the issue that I'm seeing as a clinician is that we have these legitimate, normal, healthy responses to stressful situations, and there is a limited amount of things that are available to help you to deal with them, other than "put a smile on your face and think happy thoughts." But there's no other way for me to say it: that's crap. That doesn't work if you're really redlining, from a stressful situation; there's no "just breathe, just think happy thoughts." We're always asking people of color to do this when they've dealt with these racist situations, and they've dealt with the racist boss, and they've dealt with racist cops, and they've dealt with community traumas, and they've dealt with - you know, fill the blank in, right, because the blank is long, and we can just talk about the list all day long. So that's where the \#getSHARP program comes from.

I have been trying to work with my local community activists: "Come take this class with me, let me show you all these really wonderful things you can do with your ears." And so now there's no risk of reinjury, there's no dealing with racism and the lack of racial literacy, there's something that you can do every single time you feel triggered! Now we have ways of being able to close some of those health disparities gaps, simply because we have a better tool and a better mechanism for dealing with the stress. When I go to the meetings of how to deal with the fact that we need resiliency in our communities, it's always aromatherapy, yoga, maybe some tai chi. No one talks about acupuncture. Because it's scary, it's frightening: you're going to stab people with tiny little pins. It calls up too much iatrophobia. It calls up too many ideas of medical racism. So I'm like, "Well, great! Y'all take this [ear seeds]."

The class that I've made includes: why it works, the science; things to be aware of; how to find the anatomy; the history of it; some evidence-based research studies that have been presented on the efficacy of ear seeds and auricular acupressure. ${ }^{38}$ I'm going back to add the part about electrical stimulation of the vagus nerve in the ear. ${ }^{39}$ People should have the right to the

37 The vagus nerve is the tenth cranial nerve and "represents the main component of the parasympathetic nervous system, which oversees a vast array of crucial bodily functions, including control of mood, immune response, digestion, and heart rate" (Breit et al. 2018). A branch also runs into the ear. Electrical stimulation of the vagus nerve is already a biomedical therapy for controlling epileptic seizures, and scientists are studying how it might be used to treat other conditions.

38 A form of auricular acupuncture called "battlefield acupuncture" is used to treat chronic pain in military medical facilities operated by the US Department of Defense and Veterans Administration. See, for example, Giannitrapani et al. 2020.

39 An overview of scientific research into auricular vagus nerve stimulation is Kaniusas et al. 2019. 
information; it should be widely disseminated. The hush-hush, secretive, controlling attitude behind this medicine shouldn't be there. We need to be able to make this more inviting to the individuals who can best benefit from it. Everyone can benefit from ear seeds, but for $m e$ and my goal of addressing the health disparities gap in the African American community, pretty ear seeds or even masculine [ones] because we have to get the guys in there too - is the way to go! And then, [when] brushing your teeth today, or doing your hair, it's like: "Sis, where your ear seeds at?" These need to be common conversations in melanated communities. That's my goal.

Wu: One of the things you mentioned is that you're trying to convince people. Does class intersect with race to shape the way that the African American community is or is not interested in acupuncture and Chinese medicine?

Dandridge: Class in terms of affordability is a thing, right? And it's also a geographical issue. Again, in the East Coast, my practice was supported 100 percent by melanated bodies. Every now and then when I got the one random white person that would show up in my waiting room, they definitely had that "I don't belong here," deer in the headlights kind of look.

So, it's not that all melanated individuals can't afford acupuncture. Some of the richest Black ZIP [postal] codes are on the East Coast, so there was money there to be able to support that. But the reality in this country is that there is also an income disparity between white people and Black people. Acupuncture isn't covered by insurance; if it is, there's a whole bunch of strings and tape attached to it, and so it's inaccessible to a lot of individuals. And if the question is whether or not we have enough gas money or enough food money or enough diaper money, and it's not something that is being supported by your doctors, by your insurance, by your fill-in-the-blank things, then it becomes unimportant to individuals when you're talking about regular survival. Being that the bulk of the country's poor people have been systematically forced to be African Americans through the racist policies of this country, ${ }^{40}$ it matters if acupuncture is not affordable.

40 Voluminous studies have analyzed how generations of racist violence and discriminatory government policies destroyed and displaced African American communities and impeded African Americans' socioeconomic mobility and ability to accumulate familial wealth. Two important studies are Katznelson 2005 and Rothstein 2017. This year notably marks the hundredth anniversary of the Tulsa Massacre in Oklahoma in 1921, when a white mob destroyed the Greenwood district, known as "Black Wall Street." See Tulsa Historical Society and Museum, n.d. For a recent study of how racism continues to perpetuate Black economic precarity even at higher income levels see USCJEC 2020. While 
[When] I started practicing in 2009 [in Baltimore], I had people from all classes. I had people who could only afford to come once a month, and that's what they did. They came, I loved on them really hard, they got their herbs, they got their acupuncture, they got their treatment. And then they would save up their money and they would come back. And there were people who came once a week, because they could afford to come once a week. So everybody came. There was also less serial forced displacement on the East Coast because even if people got pushed out of their neighborhoods, they didn't get pushed far, and we had the history of Lincoln [Detox Center] in New York. So we had a lot of great African American healers, one of whom was my mentor at the time, who had been in practice for almost thirty years. In the community of Baltimore, people were accustomed to, "This man is about to stick you with some needles. But don't trip, 'cause it's gonna be wonderful." So, class wasn't as much of an issue on the East Coast.

But then when I moved to the West Coast, I really had to think about [class]. When I finally opened up my business and I set a rate, I had to think about the fact that I could not afford me. What does that look like for other individuals who can't afford me but still need the medicine and the healing? Here enters POCA, right? So I met my first POCA clinician, I went to my first POCA class, and I was like, "This is wonderful!" And I still think it's wonderful. I just don't have the qi for a community acupuncture clinic; that is just not something that my body can support.

So what do I do to bridge the gap? First and foremost is simply education. Because not all poor people are destitute poor, and they can come up with some economic resources to pour in toward their health. I'm also trying to get people out of the "take something" [medication] mentality. I'm very opposed to this idealization that if I take this magic whatever, it's going to get better. I want people to get more into the habit of the "do something" mentality. This is why I came up with the "Slow-Down Sunday" class, this sliding-scale [fee] class that was two hours long. It was an inner city mini-retreat, where you could come in and then you'd learn some acupressure. You'd learn about some foods. You'd learn how to do some tai chi. You took home some ear seeds. You had an experience with live music. At the end we had drumming. And these

the absolute number of Black Americans in poverty (8.1 million in 2019) is numerically smaller than the number of non-Hispanic whites in poverty (14.2 million), the poverty rate among Black Americans (18.8 percent) is higher than for any other ethnic group, and more than 2.5 times higher than for non-Hispanic whites (7.3 percent). As a result, while Black people comprise 13.2 percent of the US population, they make up 23.8 percent of those in poverty. The median income for Blacks in 2019 (\$45,438) was also significantly lower than that for non-Hispanic whites $(\$ 76,057)$. See Semega et al. 2020, 4-5, 15 . 
were all re-creatable things that you could go home and do. Here's your packet, take it home with you. Right? Here's a do, for you, based on traditional Chinese medicine.

So class totally plays a part, but I don't think that it has to. But that requires education, not only of John Q. Public, or the Everyday Dre; ${ }^{41}$ it plays a part in the acupuncturist's understanding of how this medicine can be applied. Acupuncturists need to know how to disseminate information that people can $d o$ at home for their own wellness and their own well-being. Anybody can take blood pressure. This is not a complicated procedure, right? But if you don't know how to do it, it does look like smoke and mirrors. Then when you've done it like, twenty or thirty times, then not only can you do it for yourself, but you can do it for your aunt and your uncle and your grandpa and your kid, and it's normal to do these things. The doing is not yet normalized in our community, we are still the "take a pill, and it'll be magically better" kind of mentality, and I want that to stop. Because if you can't afford the pill, then what?

The pop-ups I work with, it's a group called Designing Justice + Designing Spaces. It's this beautiful sister named Brandi Mack, and she took mobile [health] to this whole other level. She would mobilize these community events, and these community structures that were collapsible and movable, and this whole thing would just pop up in a couple of hours. She paid for acupuncturists and massage therapists and sound therapists and yoga therapists, and all these healers to come out and to provide healing for the community. The community didn't have to pay us; we were paid by an organization. And we had the Black vendors: Black food vendors and the Black clothing vendors and the Black jewelry-makers, and people would do haircuts and they would do art, and they would have drumming, and they would have local artists. It was this whole healing city that would spring up and collapse. She had a whole bunch of them planned, and we were all excited, and then there was Covid. ${ }^{42}$

So, class plays a part, but it doesn't have to. There are models of change that can be implemented for African American communities where they can be protected from harm and not only help to rebuild their health but help build up economics. We were paid by an organization to provide a service to individuals

41 In the US the phrase "John Q. Public" is used to refer to a hypothetical, nonspecific member of society. Dandridge is using the expression "Everyday Dre" in an analogous way to refer to members of the Black community. Dre is a clipped form of Andre, notably used by the American rapper, producer, and entrepreneur Dr. Dre (Andre Romelle Young, b. 1965). The CDC confirmed the first case of COVID-19 in the US on January 21, 202O. On March 19, 2020 , in response to surging case numbers, California became the first US state to issue a statewide stay-at-home order, forbidding residents to leave their homes except for essential activities. See "Timeline" 2020. 
who would not ordinarily feel safe around white practitioners; everybody who did something at this event were melanated individuals. So we've taken away the price, we've taken away the safety issue, we've taken away the reinjury issue, and - more importantly - we have introduced the importance of healing within a group setting and a community.

It is super important that Meemaw and Papaw and Auntie So-and-So and Uncle Such-and-Such and Sister Such-and-Such and Brother Whoever are there as a unit, getting that healing. Because then they all go away and they all tell the same stories, like: "You know, I was skeptical. But then she put that needle in me and oh my back felt better"; like, "I know, I know, I took my blood pressure the next day and it came down by twenty points"; like, "Oh man, you remember my knee problem? Look at this, I can do my twerk again." You have these stories that are happening in this collective unit, and they're recirculating within this collective unit, and they're helping each other to understand that healing within the collective unit. And so this community story is now beginning to happen with this model, which is why I like mobile acupuncture.

Yesterday I went to go see a mom. The mom was like, "My husband is stressed," and because I'm there he can't tell me no. Then the kid comes home, and he's had an eight-hour hike. And he's like "Oh my god, Tenisha's here. Can I have a treatment?" And his little friend is there, and "Ooh, Mom, can I have a treatment too?" This community healing happens under these kinds of circumstances that don't happen in the sterile clinic environment. So I want to change how we think about the utilization of this medicine in this country, because it erases the class problem, it erases the money problem, it erases the iatrophobia, it erases the lack of history, it erases the lack of stories, it erases all these little nitpicky things that are boulders in terms of getting access to care.

Wu: Medicine is a thing that people do in a particular setting, and reimagining the different settings and different modes of communicating is fascinating. We [at Asian Medicine] publish a lot of articles on different kinds of international contexts, and I think that the communal aspect of healing is weak in the US and much stronger elsewhere.

Dandridge: It is! You know, I've never been to China to see how they do acupuncture, but I've heard all the stories: there's just people piled up in a room! And the doctor just comes around and does the little stabbage, and maybe there's an assistant who helps out with needles. It is not what we do in the US! We have this miscommunication that acupuncture is a procedure, as opposed to a regular lifestyle change. That's what I really want to change because it's that procedure thing that really triggers iatrophobia in African American 
communities, like, "What are you doing to me?" And if you combine that with the history of medical apartheid, ${ }^{43}$ the history of medical bias, and the history of lack of empathy and sympathy with melanated bodies, there is this huge fear around utilizing anything with a needle in Black communities. It is important to see people doing it.

When we did the Mandela Grocery Store pop-up [clinic] in Oakland, people could just see! And that was important that people could just see what it is, so I can feel comfortable with my own two eyes, and not your secondhand story of what you experienced. They've seen Sister So-and-so bring her mother, her dad, and her kids. They're skipping off and they're doing all right and they're telling these happy stories. They can see that there's nothing terrifying here; there is no curtain, there's no little man behind the curtain, there's no side effects. There's nothing to be afraid of, right?

That is how you deal with the classism: get the medicine out of the clinics and into the communities. But it has to be done in a way that I [as a practitioner] still can eat. That was the downfall of the free [Black] Panther clinics: there wasn't enough money. People were killing themselves trying to make this medicine free. We need top-down tricklenomics to happen with this medicine. We need Kaiser [Permanente] to say, "Here's your ninety grand; please go do this thing." ${ }^{44}$ We need Uc Davis to say, "Here's your six figures [salary] and all the fringe benefits, please go do this thing." We need [California] Governor Newsom to say, "Here's the task force of acupuncturists who are going to go out into the community, and here is a decent living wage and here are your benefits and here's your retirement, and please go do this thing." Right? So now we're not dealing with classism: I get to eat; they get to get needled; and we've removed this barrier. But so long as it is this bourgeois thing - a clinic behind closed doors - that's not going to happen. At the bare minimum, we need to get the needles out into the community.

Wu: What we are trying to do in this particular moment around the world is envision, "What is this going to look like in the post-COVID era?" So, where do you see yourself five years from now? Ten years from now? What are you hoping to see that would be a realization of some of these goals that you've been talking about?

43 The phrase "medical apartheid" was coined by Harriet Washington in her award-winning book on the history of medical experimentation on Black Americans. See Washington 2006.

44 Kaiser Permanente, headquartered in Oakland, CA, is one of the largest not-for-profit healthcare and insurance systems in the US, and it is the dominant "health maintenance organization" (HMO) in the state of California. See "Fast facts," n.d. 
Dandridge: If I can wave my magic wand and get all the things that I want because that's what that question says to me - I am definitely going to be in charge of somebody's research. Somebody's going to pay me to do all this reading [laughs], and to have all of these big ideas. And me hopefully transitioning to more of a national level kind of position where I can begin to be a part of national changes in how this medicine needs to be disseminated.

I don't see the pop-ups going away because you can do social distancing in open-air pop-ups. I see tent cities popping up for medicine, so that people can still come and have that gregarious, non-closed-door experience. I see people who are \#getSHARP instructors helping people with point locations and different combinations of points, so that we're going to have a better understanding of how we can incorporate this medicine into our daily lives, to deal with all life's daily little ills that will run amok in the human body.

I see that there will be a national coalition of African American acupuncturists who are beginning to disseminate information on the utilization of acupuncture to treat transgenerational trauma, and racial battle fatigue, and that this coalition of African American acupuncturists will have a core class that they will be able to take from us. I see us having our second or third annual conference of Black acupuncturists and coming together and figuring out, "Hey, we've gotten the ear seed thing to be pretty awesome and amazing, what's the next thing that we're going to work on disseminating into communities." And being very much like Acupuncturists Without Borders, but we'll be Black Acupuncturists Without Borders.

I want us to be on our third or fourth or fifth round of scholarships, and us seeing our first round of graduates of the scholarships that we sponsored. And when we sponsored scholarships in the first year we only got ten people, but the second year's coming and there's thirty, and the third year has fifty, and the fourth year is like, "Oh my god. There's a hundred of them and we've paid for them and they're coming." They're coming so that we can - oh, I'm going to cry - because we need help. Right? And we need more of us, and we need to know. And we just - we need so much.

I want there to just be so many more hands on deck, because I remember when I started going to [acupuncture] school in 2005, there were three Black students in the room. By the time I graduated, $I$ was the Black student in the room, because [the school] wasn't supportive of its melanated students. And so I want there to be a Harlem Institute of Acupuncture where there are Black teachers and there are Black students, and we have outreach programs into melanated schools. And now there are little Black kids who are learning how to do cupping and know how to do seeds and teaching people how to do gua sha and it's normal in our community, and we have sellout venues [with] people 
who want to learn how to bring this information into their community and we just can't pour money fast enough into that movement.

I lost my grandmother; she was like the best part of my family for me. And my aunt is getting older and she's the closest thing that I have to that. And I'm watching people die from CoviD and it doesn't have to happen. We don't need to die, but we have all the preexisting conditions ${ }^{45}$ And they're not being managed and they're not being addressed, and acupuncture needs to be there to be able to help!

So I want stadiums of people who are learning how to do cupping and learning how to push on [the point] Spleen-6. I want there to be the Mardi Gras of traditional Chinese medicine and Black acupuncture; I want there to be the Essence Fest of Black acupuncture. ${ }^{46}$ I know that we can't gather [because of COVID], but there still needs to be these huge movements and these huge gatherings of Black people where it's just like, "That's acupuncture week, and I'm going to go learn the OB-GYN part of it now." I want that Black midwives are learning acupuncture so that we can close the health disparities gap around the fact that we die trying to give birth! I was one of them - I almost died trying to give birth. This is insane: we are one of the richest countries on the planet, and yet we have women who are regularly dying, and we have children who are regularly dying, just trying to be in the world ${ }^{47}$

So that is my goal. I want sellout venues. I want there to have to be a hundred acupuncturists working full time trying to disseminate information as fast as humanly possible because we cannot make classes fast enough. I just want to be a part of the change to help my people to be better. And I'm not trying to be prejudiced or selfish or racist, because as I said, transgenerational trauma and racial battle fatigue are a thing globally. Those are some of the huge dreams that went off. I can just wave my magic Harry Potter wand and do "Expecto Patronus." There will be this wave and this light of love and happiness and

45 A recent study of Covid deaths in thirty-five states found that overall standardized age-indexed mortality rates were 2.7 times higher for Black people than white people. In individual states, the higher rates of Black deaths ranged from 1.4 (Oklahoma) to 4.5 (Michigan). The study also found a correlation between increased levels of structural racism and increased racial disparities in COVID mortality. See Siegal 2021.

46 Essence is a lifestyle magazine aimed at an African American female readership. It sponsors an annual music festival known colloquially as Essence Fest.

47 The most recent statistics (for 2018) show a US maternal mortality rate of 17.4 per 100,000 live births, with non-Hispanic Black women suffering maternal mortality rates as much as two to three times higher than non-Hispanic white women (CDC 2020). In 2017 an investigative journalism series on the high rate of preventable maternal deaths in the US highlighted the fact that preventable Black maternal deaths occur across all socioeconomic classes (Martin and Montagne 2017). 
healing that can be disseminated throughout the community. I'm sorry, I didn't mean to get all emotional -

Wu: You've given us so much to think about, and I'm grateful to you for taking so much time to talk.

Dandridge: Thank you for hearing my stories and thank you for asking me important questions. We need to have these conversations. The 77 percent or whatever of people who practice this medicine [who are white], ${ }^{48}$ they need to have some racial competency, some racial literacy, they need to deal with their white fragility.9 ${ }^{49}$ It's just like acupuncture! If you don't keep treating it, it's not going to get better! It's going to revert, because it's too easy to revert, because the racism is in the air we breathe in this country. I tell people: racism and dealing with racism is like a dirty kitchen. The crazy racists - like the KKK people and the David Duke people, the truly nasty people - are like the roaches that end up in a dirty kitchen. ${ }^{50}$ And you can't be mad at the roaches if you don't clean up the kitchen! You're feeding them. You're sheltering them. You're harboring them. You're making it easy for them to lay their little nasty egg sacs everywhere and to feed the children that come up out of this. White silence is white compliance is white violence. You are allowing this to continue. Eight minutes and forty-six seconds. ${ }^{51}$ Why didn't someone rock the goddamn boat?

48 Job analysis reports produced for the National Certification Commission for Acupuncture and Oriental Medicine compiled demographic data based on the self-reported identities of US acupuncture practitioners responding to an online survey. In 2013 there were 1,543 respondents, and 76.9 percent of them self-identified as white. In 2017 there were 2,945 respondents who answered the question on race, of which 68.8 percent were white. To contextualize these changes in percentages, one might note that the percentage of "Asian" practitioners increased from 16.6 percent (in 2013) to 19 percent (in 2017) and those who "prefer not to answer" increased from 0.2 percent (in 2013) to 5 percent (in 2017). The 2017 survey also provided respondents with a new category - "two or more races" - which constituted 3.7 percent of all responses. The number of self-identified Black practitioners responding to the survey was 1.2 percent in 2013 (18 people) and o.8 percent (24 people) in 2017. See Wang 2013; Ward-Cook 2017.

49 American scholar Robin DiAngelo coined the term "white fragility" in 2011 to describe the psychological orientations that cause whites to react with hostility, defensiveness, and denial when discussions of racism and racial inequity arise. For her book on the subject see DiAngelo 2018.

50 The Ku Klux Klan is a white supremacist organization. David Duke (b. 1950) is a former ккк leader who formerly served in the Louisiana state legislature and ran unsuccessfully for various national offices, including that of US president.

$5^{1} \quad$ The initial prosecutor's report stated that police officer Derek Chauvin knelt on George Floyd's neck for 8 minutes and 46 seconds. See Levenson 2021. 
This man [George Floyd] called for his mama [as the police officer asphyxiated him]. Why didn't someone rock the boat?

So we need to constantly rock that boat. We need to pick up the toaster oven and get underneath it, not just in front of it. We need to make sure that there's not crumbs somewhere, because every one of those little instances is one more instance for that roach to survive and to breed. And you are allowing them because you are not taking care of business. You have to stay on top of it. And if we don't get to that point - not just in the acupuncture community but in our colonized countries - then this thing doesn't go away, and it'll come back. Any disease that you get rid of can come back if you're not taking care of it, and racism is absolutely a goddamn disease! It is a cancer. It is insidious, and it's quiet, and it's silent, and it needs not to be.

\section{Acknowledgments}

Special thanks to Colin Garon for transcribing this interview, and to Daniel Burton-Rose, Anna Andreeva, and Nicole Barnes for their editorial feedback and suggestions.

\section{About the Interviewer}

Yi-Li Wu is an associate professor of women's and gender studies and history at the University of Michigan, Ann Arbor. She is the author of Reproducing Women: Medicine, Metaphor, and Childbirth in Late Imperial China (University of California Press, 2010) and is completing a manuscript on the history of medicine for injuries in China. She is the Senior Editor of Asian Medicine.

\section{Bibliography}

"Acupuncture Board History." No date. State of California Department of Consumer Affairs Acupuncture Board website. https://www.acupuncture.ca.gov/about_us/ history.shtml.

Bellware, Kim. 2020. "Calls to Declare Racism a Public Health Crisis Grow Louder Amid Pandemic, Police Brutality." Washington Post, September 15. https://www .washingtonpost.com/nation/2020/o9/15/racism-public-health-crisis/. 
Breit, Sigrid, Aleksandra Kupferberg, Gerhard Rogler, and Gregor Hasler. 2018. "Vagus Nerve as Modulator of the Brain: Gut Axis in Psychiatric and Inflammatory Disorders." Frontiers in Psychiatry 9: 44. https://doi.org/10.3389/fpsyt.2018.00044.

Burton-Rose, Daniel, and Yi-Li Wu. 2021. "Acupuncture, the Black Panther Party, and People's Medicine: An Interview with Physician-Activist Tolbert Small." Asian Medicine 16, no. 2: 251-75.

CDC (Centers for Disease Control and Prevention). 2020. "First Data Released on Maternal Mortality in Over a Decade." Press release, January 30, 2020. https://www .cdc.gov/nchs/pressroom/nchs_press_releases/2020/202001_MMR.htm.

Cooper Owens, Deirdre. 2021. "Listening to Black Women Saves Black Lives." The Lancet 397, no. 10276 (February 27, 2021): 788-89. https://doi.org/10.1016/So14O $-6736(21)$ oo367-6.

Dandridge, Tenisha. 2020. "Unusual Tale of Acupuncture, Racism, and African American History in the USA." Everyone's Place, June 7, 202O. www.everyones-place .com/bipoc-health/unusual-tale-of-acupuncture-racism-and-african-americanhistory-in-the-usanbsp.

DeAngelis, Tori. 2019. “The Legacy of Trauma." Monitor on Psychology 50, no. 2 (February): 36-43. https://www.apa.org/monitor/2019/o2/legacy-trauma.

DeGruy, Joy. 2017. Post Traumatic Slave Syndrome: America's Legacy of Enduring Injury and Healing. Revised ed. Portland, OR: Joy Degruy Publications Inc.

Diamond, Jeremy. 2016. "More than 2 Dozen Black Lives Matter Protestors Disrupt Trump Rally." $C N N$, March 4, 2016. https://www.cnn.com/2016/o3/o4/politics/ donald-trump-protesters-black-lives-matter.

DiAngelo, Robin. 2018. White Fragility: Why It's So Hard for White People to Talk About Racism. Boston, MA: Beacon Press.

Donovan, Mia, dir. 2020. Dope Is Death. Documentary. 82 minutes. Montreal, Canada: EyeSteelFilm.

"Fast facts." No date. Kaiser Permanente website. www.about.kaiserpermanente.org/ who-we-are/fast-facts.

Furth, Charlotte. 1999. A Flourishing Yin: Gender in China's Medical History, 960-1665. Berkeley: University of California Press.

Giannitrapani, Karleen F., Princess E. Ackland, Jesse Holliday, Steve Zeliadt, Juli Olson, Benjamin Kligler, and Stephanie Taylor. 2020. "Provider Perspectives of Battlefield Acupuncture: Advantages, Disadvantages and Its Potential Role in Reducing Opioid Use for Pain." Medical Care 58, no. 9, suppl. 2 (September): S88-S93. https://doi .org/10.1097/MLR.oooooooooooo1332.

Glenn, Evelyn Nakano. 2008. "Yearning for Lightness: Transnational Circuits in the Marketing and Consumption of Skin Lighteners." Gender \& Society 22, no. 3: 281302. https://doi.org/10.1177/0891243208316089. 
Hoffman Kelly M., Sophie Trawalter, Jordan R. Axt, and M. Norman Oliver. 2016. "Racial Bias in Pain Assessment and Treatment Recommendations, and False Beliefs about Biological Differences Between Blacks and Whites." Proceedings of the National Academy of Sciences of the United States of America 113, no. 16: 4296-301. https://doi .org/10.1073/pnas.1516047113.

Institute of Medicine (US) Committee on Understanding and Eliminating Racial and Ethnic Disparities in Health Care. 2003. Unequal Treatment: Confronting Racial and Ethnic Disparities in Health Care. Washington, DC: National Academies Press.

Johnson, Jenna, and Mary Jordan. 2015. "Trump on Rally Protestor: 'Maybe He Should Have Been Roughed Up'” Washington Post, November 22, 2015. https://www .washingtonpost.com/news/post-politics/wp/2015/11/22/black-activist-punched -at-donald-trump-rally-in-birmingham/.

Kaniusas, Eugenijus, Stefan Kampusch, Marc Tittgemeyer, Fivos Panetsos, Raquel Fernandez Gines, Michaele Papa, Attila Kiss, et al. 2019. "Current Directions in the Auricular Vagus Nerve Stimulation I: A Physiological Perspective." Frontiers in Neuroscience 13, article no. 854. https://doi.org/10.3389/fnins.2019.0o854.

Katznelson, Ira. 2005. When Affirmative Action Was White: An Untold History of Racial Inequality in Twentieth-Century America. New York: W.W. Norton \& Co, Inc.

Levenson, Eric. 2021. "Former Officer Knelt on George Floyd for 9 Minutes and 29 Seconds - Not the Infamous 8:46," $c N N$, March 30, 2021. https://www.cnn.com/ 2021/O3/29/us/george-floyd-timing-929-846/index.html.

Lockhart, P.R. 2018. "What Serena Williams's Scary Childbirth Story Says About Medical Treatment of Black Women." Vox, January 11, 2018. https://www.vox.com/ identities/2018/1/11/16879984/serena-williams-childbirth-scare-black-women.

Martin, Nina, and Renee Montagne. 2017. "Nothing Protects Black Women From Dying in Pregnancy and Childbirth.” ProPublica, December 7, 2017. https://www.pro publica.org/article/nothing-protects-black-women-from-dying-in-pregnancy-and -childbirth.

Maryam, Abedini, Aminzadeh Fariba, Manshoori Azita, Bakhtar Babak, and Sadeghi Tabandeh. 2020. "The Effects of Auriculotherapy on Shoulder Pain After a Cesarean Section." Journal of Acupuncture and Meridian Studies 13, no. 5: 157-62. https://doi .org/10.1016/j.jams.2020.09.002.

Meng, Eana. 2021a. "Photo Essay: Bringing Acupuncture to the People: Tolbert Small in China and California." Asian Medicine 16, no. 2: 276-94.

Meng, Eana. 2021b. "Reflections on (Re)making History: African American Acupuncturists and the Archives of Tolbert Small." Asian Medicine 16, no. 2: 295-309.

NADA (National Acupuncture Detoxification Association). 2020. "NADA Celebrates the 5oth Anniversary of the Takeover of Lincoln Hospital." November 10, 2020. https://acudetox.com/nada-celebrates-5oth-anniversary-of-the-takeover-of -lincoln-hospital/. 
NADA. 2021. "NADA Full Circle: Looking Back into the Future." Event 1 recording, March 26, 2021. https://acudetox.com/nada-full-circle-looking-back-into-the-future -part-1-recording/.

Nelson, Alondra. 2011. Body and Soul: The Black Panther Party and the Fight Against Medical Discrimination. Minneapolis: University of Minnesota Press.

Park, Jenny, Mary Catherine Beach, Dingfen Han, Richard D. Moore, P. Todd Korthuis, and Somnath Saha. 2020. "Racial Disparities in Clinician Responses to Patient Emotions." Patient Education and Counseling 103, no. 9: 1736-44. https://doi .org/10.1016/j.pec.2020.03.019.

Payne, Keith B. 2017. The Broken Ladder: How Inequality Affects the Way We Think, Live, and Die. New York: Viking.

People's Doctor Murdered! No date. Pamphlet. New York: Come! Unity Press. http:// www.freedomarchives.org/Documents/Finder/DOC58_scans/58.White.Lightening .RichardTaft.pdf.

Phan, Tyler. 2017. "American Chinese Medicine." PhD. diss, Department of Anthropology, University College London. https://discovery.ucl.ac.uk/id/eprint/1571107/1/American \%20Chinese\%2oMedicine\%2o-\%2oFINAL.pdf.

Rothstein, Richard. 2017. The Color of Law: A Forgotten History of How Our Government Segregated America. New York: Liveright Publishing.

Semega,Jessica, Melissa Kollar, Emily A. Shrider, and John F. Creamer. 2020. Income and Poverty in the United States: 2019. US Census Bureau, Current Population Reports, No. P6o-270. Washington, DC: US Government Publishing Office. https://www .census.gov/content/dam/Census/library/publications/2020/demo/p6o-27o.pdf.

Siegel, Michael, Isabella Critchfield-Jain, Matthew Boykin, and Alicia Owens. 2021. "Actual Racial/Ethnic Disparities in COVID-19 Mortality for the Non-Hispanic Black Compared to Non-Hispanic White Population in 35 US States and Their Association with Structural Racism." Journal of Racial and Ethnic Health Disparities (April 27, 2021). https://doi.org/10.1007/s40615-021-01028-1.

Smith, William A. 2004. "Black Faculty Coping with Racial Battle Fatigue: The Campus Racial Climate in a Post-Civil Rights Era." In A Long Way to Go: Conversations About Race by African American Faculty and Graduate Students at Predominantly White Institutions, edited by Darrell Cleveland, 171-9o. New York: Peter Lang.

Stallings, Erika. 2018. "The Article That Could Help Save Black Women's Lives." O. The Oprah Magazine, October 2018. https://www.oprah.com/health_wellness/ the-article-that-could-help-save-black-womens-lives.

Stinson, Claire, and Emily Bucherati. 2020. "The Hear HerCampaignEmpowers Pregnant and Postpartum Women." CDC Foundation blog, August 10, 2020. https://www.cdc foundation.org/blog/hear-her-campaign-empowers-pregnant-and-postpartum -women. 
Sue, Derald Wing, Christina M. Capodilupo, Gina C. Torino, Jennifer M. Bucceri, AishaM.B.Holder, Kevin L. Nadal, and Marta Esquilin. 2007. "Racial Microaggressions in Everyday Life: Implications for Clinical Practice." American Psychologist 62, no. 4: 271-86. https://doi.org/10.1037/ooo3-066X.62.4.271.

“Timeline: California Reacts to Coronavirus." 2020. CalMatters. https://calmatters.org/ health/coronavirus/2020/o4/gavin-newsom-coronavirus-updates-timeline/.

Tulsa Historical Society and Museum. No date. "1921 Tulsa Race Massacre." Online exhibit. https://www.tulsahistory.org/exhibit/1921-tulsa-race-massacre/.

usCJEc (United States Congress Joint Economic Committee). 202O. The Economic State of Black America in 2020. June 11, 2020. https://www.jec.senate.gov/public/ _cache/files/ccf4dbe2-810a-44f8-b3e7-14f7e5143ba6/economic-state-of-black -america-202O.pdf.

Veracini, Lorenzo. 2016. "Introduction: Settler Colonialism as a Distinct Mode of Domination." In The Routledge Handbook of the History of Settler Colonialism, edited by Edward Cavanaugh and Lorenzo Veracini, 1-8. London: Routledge.

Wang, Zijian Gerald. 2013. Foundations of Oriental Medicine, Biomedicine, Acupuncture with Point Location, Chinese Herbology, Job Analysis Report 2013. National Certification Commission for Acupuncture and Oriental Medicine. https://www.nccaom .org/wp-content/uploads/pdf/NCCAOM_2013_JA_Report.pdf.

Ward-Cook, Kory. 2017. The 2017 NCCAOM Job Analysis Survey: A Report for the Profession of Acupuncture and Oriental Medicine. National Certification Commission for Acupuncture and Oriental Medicine. https://www.nccaom.org/wp-content/ uploads/pdf/2017\%2oNCCAOM\%2OJob\%2oAnalysis\%2oStudy\%2oFull\%2O Report\%2owith\%2oAppendices.pdf.

Washington, Harriet A. 20o6. Medical Apartheid: The Dark History of Medical Experimentation on Black Americans from Colonial Times to the Present. New York: Doubleday.

Weeks, John. 2020. "Mending Our History: Acu-Detox Group Engages Its Black Panther and Young Lord Roots in the Time of George Floyd." Today's Practitioner, August 6, 2020. https://todayspractitioner.com/john-weeks/john-weeks-mending -our-history-acu-detox-group-engages-its-black-panther-and-young-lord-roots-in -the-time-of-george-floyd/.

Ye, Jiajia, Shuhe Cai, Wai Ming Cheung, and Hector W.H. Tsang. 2019. "An East Meets West Approach to the Understanding of Emotion Dysregulation in Depression: From Perspective to Scientific Evidence." Frontiers in Psychology 10, article 574. https://doi.org/10.3389/fpsyg.2019.00574. 